\title{
D4T1 論文 Recovery of Copper, Tin and Lead from the Spent Printed Circuit Boards (PCBs) by the Shape Separation Method ${ }^{*}$
}

\author{
by Jae-Chum LEE ${ }^{1}$, Shigeki KOYANAKA ${ }^{2}$, Minyong LEE $^{3}$ \\ Hitoshi OHYA ${ }^{4}$ and Shigehisa ENDOH $^{5}$
}

\begin{abstract}
A study on the recovery of metallic components from the spent printed circuit boards (PCBs) was conducted using a shape separation technique. PCBs were pulverized to under $1 \mathrm{~mm}$ by a swing hammer type impact mill to liberate vairous metallic components after all electronic parts were removed in advance. The milled PCBs were subjected to the shape separation process using an inclined vibrating plate (IVP) to separate metal particles from nonmetallic components. The effect of vibration intensity and inclined angle on the metal separation efficiency were investigated. The optimum operation conditions for IVP were at the vibration intensity $\left(K_{v}\right)$ of 1.40 and the inclined angle of $10^{\circ}$. By optimizing the operation conditions, it was possible to obtain the recovery and grade of the metallic components over $90 \%$.
\end{abstract}

KEY WORDS : Printed Circuit Board, Hammer Type Impact Mill, Shape Separation, Inclined Vibrating Plate

\section{Introduction}

The recycling of electronic scraps has been focused on the recovery of precious metals such as gold, silver, platinum, palladium, rhodium as well as base metals including copper, nickel, aluminum and tin. Among these, gold was obviously the one studied most for the recycling during the past thirty years (Hoffmann, 1992; Elaine, 1991).

The conventional technology for the recycling of the scrap was of the pyrometallurgical routes mostly utilizing blast furnace smelting (Setchfield, 1987; Hedlund, et al., 1985; Kaltenboeck, et al., 1985). The process was aimed at the recovery of precious metals or copper from printed circuit boards on which all type of electronic components i. e. switches, connectors, resistors, capacitors, integrated circuits chip and copper are mounted. The pyrometallurgical process has the advantage of accepting any physical form of the scrap. However, it has the drawbacks of air pollution, a loss of noble metals, generation of slag and low recovery of other metals.

The aqueous processing has the advantages of better environmental protection over thermal processes which pollutes air through the combustion of plastics and the

* Received October 31, 1996 : accepted for publication February 28, 1997

1. Senior Researcher, Ph. D., Korea Institute of Geology, Mining \& Materials, Dae - Jeon, Korea.

2. Researcher, Material Handling and Characterization Div., National Institute for Resources and Environment, Tsukuba, Ibaragi 305, Japan.

3. Visiting Researcher, Ph. D., Material Handling and Characterization Div., National Institute for Resources and Environment, Tsukuba, Ibaragi 305, Japan.

4. Senior Researcher, Material Handling and Characterization Div., National Institute for Resources and Environment, Tsukuba, Ibaragi 305, Japan.

5. Chief, Ph. D., Material Handling and Characterization Div., National Institute for Resources and Environment, Tsukuba, Ibaragi 305, Japan.

[For correspondence] FAX 0298-58-8458 (NIRE) particulate emissions from the furnace (Dunning, Jr., 1986; Krupka, et al., 1987). Under the environmental restrictions, the aqueous processing becomes the more predominant method for harmless treatment which enables the extraction of all toxic constituent from electronic scrap as well as the reclamation of valuable metals (Dunning, Jr., 1986; Edson, 1981; Masuda, et al., 1988; Day, 1984). In hydrometallugical routes, the mechanical processing is usually preceded in order to reduce the bulk of scrap and to separate the material fractions. Afterwards, the leaching of inorganic components from the scrap was followed. Therefore, it is necessary to establish the separation process of the fraction of metals by the mechanical beneficiation (Rhee, et al., 1995).

For effective treatment of electronic scraps, the physical pretreatment are necessary to make the extraction and separation of metals easier. Especially, for direct acid leaching of PCBs, many of the organic compounds contaminate the leachant making the following separation process complicate. Therefore, it is necessary to separate electronic scraps by physical means before the aqueous processes. The physical pretreatments of scraps usually comprise crush, bulk reduction, and physical separation of various components. The physical separation method for non-ferrous metals is conducted by two means: density separation or eddy-current. The eddy-current technique has a major disadvantage that it can not be applied to small particles produced inevitably during bulk reduction.

Koyanaka et al. (1995) developed the technology for recovering copper from the printed wiring board ( $\mathrm{PWB}$ ) by the physical separation. PWB scraps were pulverized by a swing hammer type impact mill and the copper component was effectively liberated from the nonmetallic components. Copper particles were then separated and collected by the shape 
sorting technique using an inclined vibrating plate.

The purpose of this study was to recover copper, tin and lead from the spent printed circuit boards (PCBs) by the shape sorting technique using an inclined vibrating plate. The effect of mill operation conditions on characteristics of milled products was investigated and a shape separation was carried out to recover metallic components as copper, tin and lead from milled PCBs. In addition, the operation parameters such as the inclined angle and the vibration intensity were investigated in order to determine the optimum conditions for the effective separation of metallic components.

\section{Experimental}

\section{$2 \cdot 1$ Materials}

The sample used in this experiment was a spent printed circuit boards (PCBs). The major metallic components in PCBs were $28.36 \%$ of copper, $1.93 \%$ of tin, and $1.14 \%$ of lead. Copper, used for wiring, consists between the thin layers of glass-reinforced epoxy resin. Lead and tin, the main component of the solder, resided on the back of the PCBs. All of electronic parts mounted on PCBs were removed prior to size reduction. PCBs was shredded to about $2-3 \mathrm{~cm}$ and then reduced to less than $3 \mathrm{~mm}$ by a vertical type cutting mill (Orient Co., Japan) before subjected to the process for liberation of metals from PCBs.

\section{$2 \cdot 2$ Metals liberation}

The crushed PCBs were milled to liberate metals from PCBs by a swing hammer type impact mill with the screen of $\phi 1.0 \mathrm{~mm}$ aperture size. Samples were fed at a feed rate of 0.5 $\mathrm{g} / \mathrm{s}$ and the rotation speed of hammers was varied from 26.5 $\mathrm{m} / \mathrm{s}$ to $61.3 \mathrm{~m} / \mathrm{s}$. The metallic components were separated from the milled products by heavy medium separation using acetylene tetrabromide (Sp. Gr. : $2.955 \sim 2.975$ ) as a heavy medium and chemically analyzed to determine the apparent degree of metal liberation.

\section{2 - 3 Particle characterization and shape separa- tion}

The milled product was classified by JIS standard sieve and the composition of major metals was determined to investigate the distribution of metals with particle size of the products. SEM was used to observe the morphology of particles

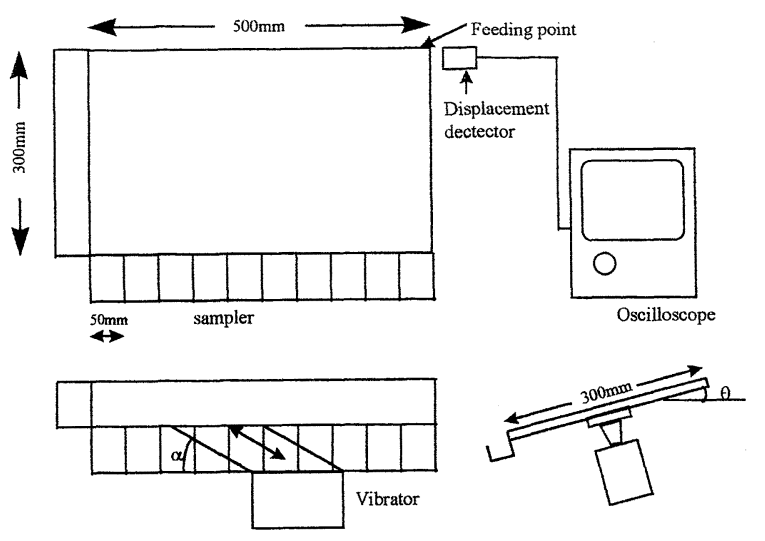

Fig. 1 Schematic diagram of Inclined vibrating plate. and EPMA for chemical analysis. The particle shape of products over $149 \mu \mathrm{m}$ was analyzed by an image analyzer (LA-555, PIAS, Japan). For the shape separation inclined vibrating plate (IVP) was used. Fig. 1 shows the schematic diagram of IVP. Shape separation was carried out with the same method described in the previous work (Koyanaka, et al., 1995). The metallic components collected at each sampler were separated from nonmetallic components by hand picking or heavy medium separation and weighed to determined the recovery distributions and Newton's separation efficiency.

\section{Results and discussion}

\section{$3 \cdot 1$ Characteristics of metal particles in milled PCBs}

Printed circuit boards (PCBs) was milled for metal liberation by a hammer mill with the screen of $\phi 1.0 \mathrm{~mm}$ aperture size. Particle size distributions of metallic components in milled PCBs are shown in Fig. 2. The size of metal particles decreased slightly with increasing the rotation speed of hammer mill. The distribution of $+297 \mu \mathrm{m}$ particles was $80 \%$ at $26.5 \mathrm{~m} / \mathrm{s}$ and continued to decrease to $66 \%$ at $61.3 \mathrm{~m} / \mathrm{s}$. It can be seen that more than $90 \%$ of metal particles remain over $149 \mu \mathrm{m}$ despite of milling. As the speed of the hammer mill increased, the metallic components having some ductility were bent and became smaller. However, further size reduction by increasing mill speed was insignificant.

Fig. 3 shows a SEM micrograph and EPMA results on metal particles after milling with the hammer speed of 26.5 $\mathrm{m} / \mathrm{s}$. Here, (a) shows the shape of eight metal particles, part of which are numbered as A to E. (b), (c), and (d) show EPMA mapping of copper, tin, and lead, respectively. As can be seen in (a), the metal particles are bent to spherical shapes and nonmetallic particles remain inside unseparated. Particles A and B should contain only copper and non-metallic components. Meanwhile, particle $\mathrm{C}$ shows copper as well as tin and lead. Particles D and E show tin and lead as major elements along with traces of copper. These observations suggest that either copper particles were included into solder or copper particles were coated with solder of low-melting temperature during milling.

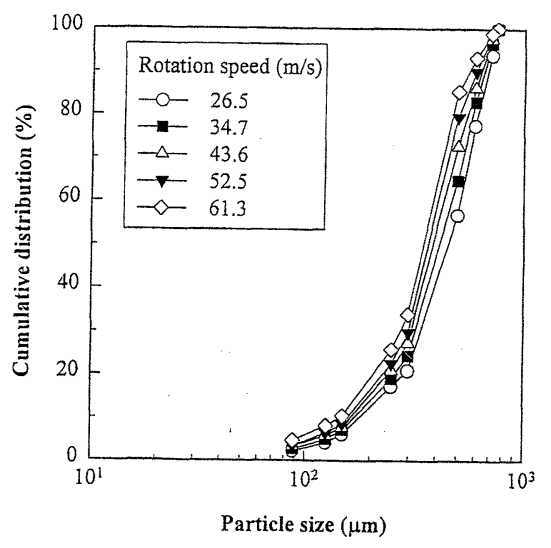

Fig. 2 Particle size distribution of metal particles in milled PCBs. 

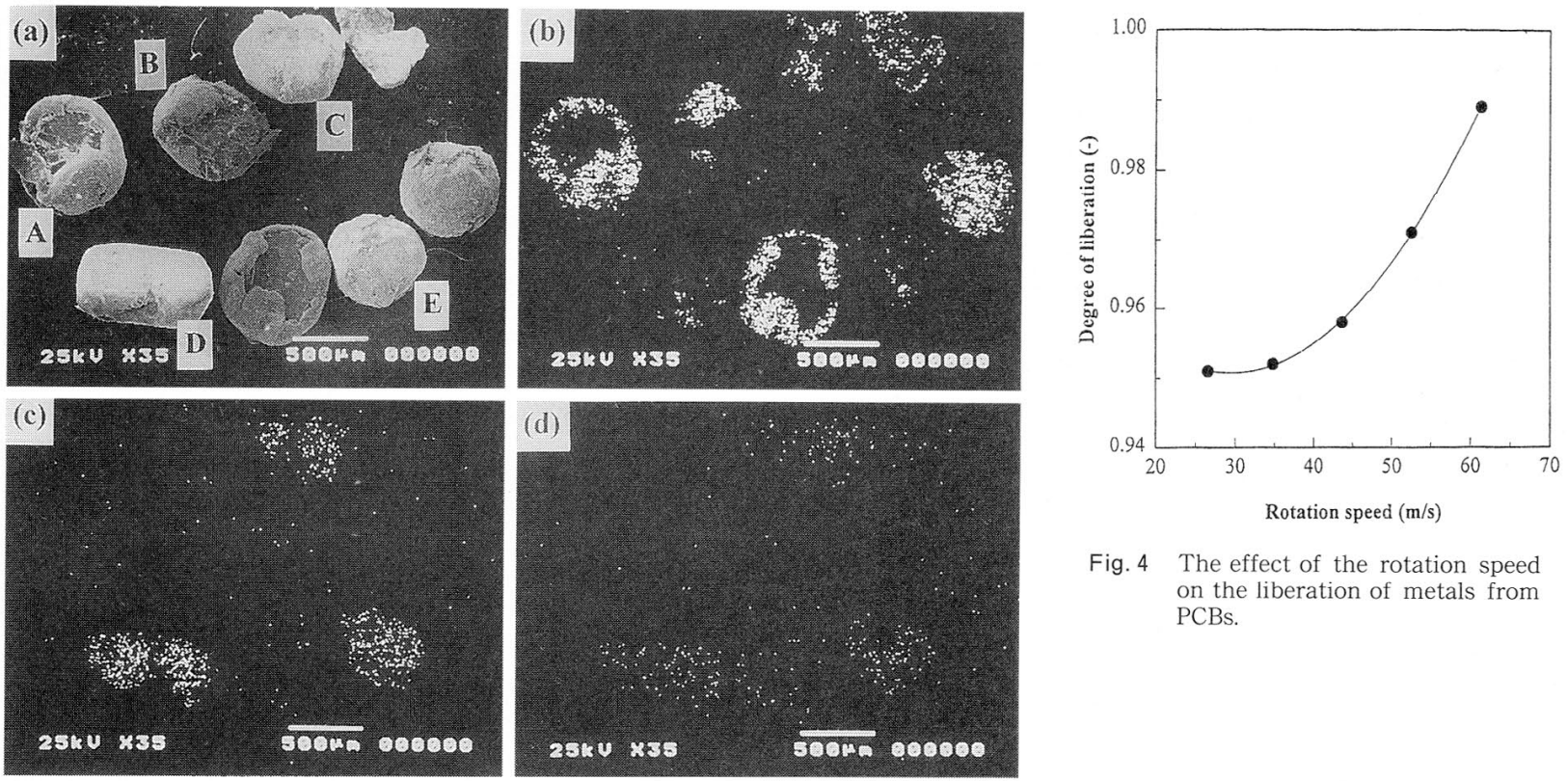

Fig. 4 The effect of the rotation speed on the liberation of metals from PCBs.

Fig. 3 SEM micrograph and EPMA results of metal particles.

(a) SEM micrograph of 8 particles. Five particles are numbered as A to E, (b) EPMA

map of $\mathrm{Cu}$, (c) EPMA map of Sn, (d) EPMA map of $\mathrm{Pb}$.

Fig. 4 shows the effect of the rotation speed of hammer mill on the apparent degree of metal liberation from nonmetallic components. The apparent degree of liberation for metallic components was defined as follows.

Apparent degree of liberation $=$

weight of metals recovered by heavy medium / total weight of metals in feed (1)

The apparent degree of liberation is shown to increase with the rotation speed and about $99 \%$ of metals can be liberated at the speed of $61.3 \mathrm{~m} / \mathrm{s}$.

Fig. 5 shows the effect of rotation speed on the distribution of metal particles. Here, (a) is for copper and (b) is for solder particles. As can be seen in Fig. 5(a), copper particles smaller than $500 \mu \mathrm{m}$ increase with the hammer speed. In the mean time, particles smaller than $297 \mu$ m does not show a significant change despite of increased rotation speed. Therefore, it is obvious that copper particles over $500 \mu \mathrm{m}$ were milled mostly into particles of $500-297 \mu \mathrm{m}$ as the milling speed increased. Obviously, this may pose a practical limitation to the size reduction of copper particles by this method.

The milling process for solder particles was found to be more effective than for copper particles. Fig. 5(b) shows the distribution of solder which is composed of tin and lead. The amount of solder particles smaller than $500 \mu \mathrm{m}$ increase sharply and become almost $100 \%$ when the rotation speed exceeds $43.6 \mathrm{~m} / \mathrm{s}$ and particles smaller than $149 \mu \mathrm{m}$ and $297-149$ $\mu \mathrm{m}$ continue to increase with the rotation speed. It is obvious that solder particles continue to become smaller as the rotation speed increases unlike the case of copper particles where the size reduction below $297 \mu \mathrm{m}$ did not occurred during milling. This phenomena can be clearly known from Fig. 6 that shows the amount of tin and lead in copper particles which were larger than $500 \mu \mathrm{m}$ after milling. It can be seen that the ratio of solder to copper decreases rapidly as the rotation

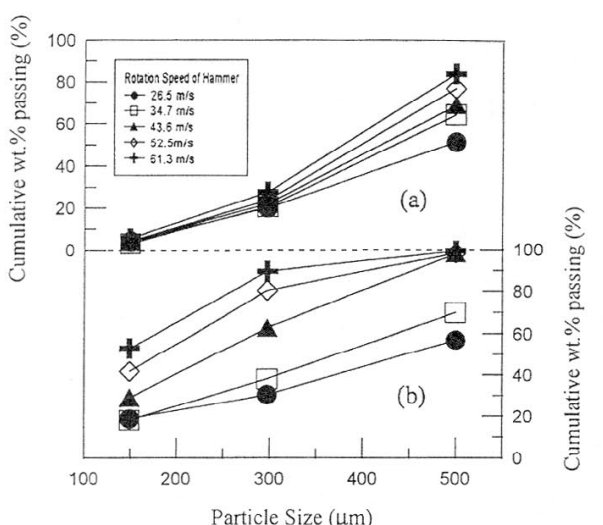

Fig. 5 The effect of the rotation speed on the distribution of metal particles.

(a) Copper particles, (b) Solder $(\mathrm{Sn}+\mathrm{Pb})$ particles.

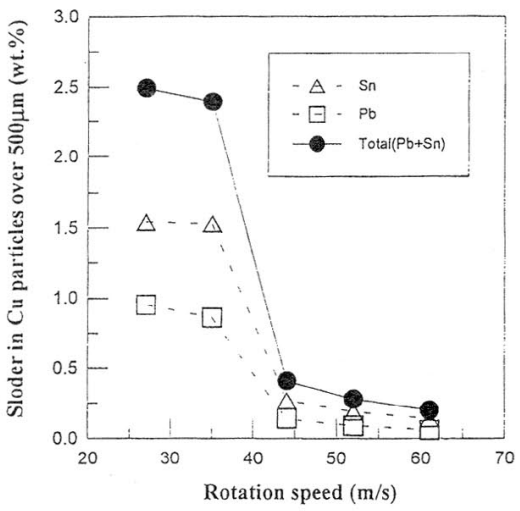

Fig. 6 The amount of solder in copper particle over $500 \mu \mathrm{m}$.

speed increases especially when it exceeds $34.7 \mathrm{~m} / \mathrm{s}$.

The solder seems to adhere easily on the surface of copper particles in the case of lower hammer speed (see Fig. 3). But, when the hammer speed becomes higher, the size of solder reduce rapidly and the solder is probably segregated from the 


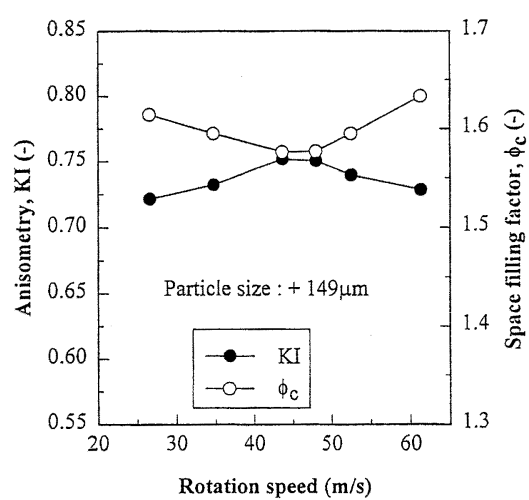

Fig. 7 The effect of the rotation speed on the anisometry $K I$ and space filling factor $\phi_{c}$ of metal particles in milled PCBs.

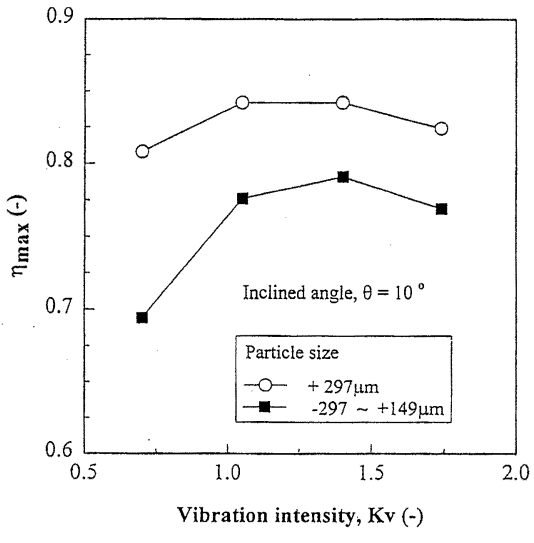

Fig. 8 The effect of the vibration intensity on the maximum Newtons' separation efficiency in the shape separation of PCBs. milled at the rotation speed of $48.6 \mathrm{~m} / \mathrm{s}$.

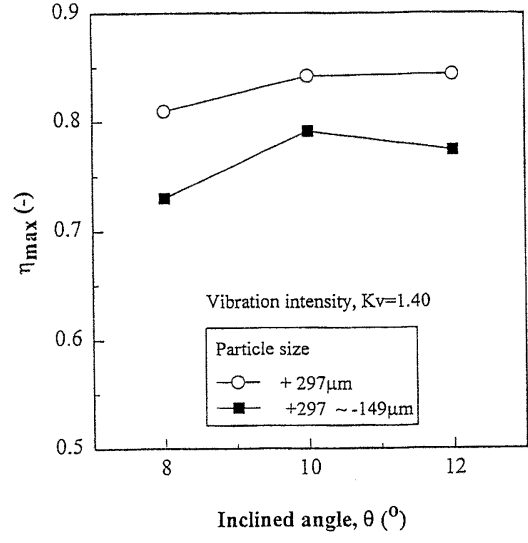

Fig. 9 The effect of the inclined angle on the maximum Newtons' separation efficiency in the shape separation of PCBs. mikked at the rotation speed of $48.6 \mathrm{~m} / \mathrm{s}$. other component of PCBs due probably to their lower melting temperature and ductility.

Fig. 7 shows the shape characteristics of milled metal particles obtained by an image analyzer. The values of anisometry $(K I)$ and the space filling factor $\left(\phi_{c}\right)$ of metal particles were obtained from the measurements of about 500 particles.

$K I$ and $\phi_{c}$ are obtained from the following equations,

$K I=a / b$

$\phi_{c}=\pi D^{2} / 4 \mathrm{~S}$

where $a$ and $b$ are the short and long principal axes of an ellipse of inertia equivalent to particle projection, $D$ is the maximum diameter in particle projection, and $S$ is the projected area of the particle. According to this definitions, both of $K I$ and $\phi_{c}$ value of spherical particle are unity. Ductile metals bend to spherical shape when they are milled in an impact mill. It can be seen that $K I$ value representing the roundness of metal particles increases slightly at low hammer speeds and decreases when it exceeds $50 \mathrm{~m} / \mathrm{s}$. Meanwhile, $\phi_{c}$ value shows the reverse trend with hammer speed. The maximum of $K I$ and minimum of $\phi_{c}$ curves in Fig. 7 indicate that the shape of metal particles is the most spherical at the rotation speed of $40 \sim 50 \mathrm{~m} / \mathrm{s}$.

\section{$3 \cdot 2$ Shape separation}

Fig. 8 shows the results of shape separation experiments on metal particles from PCBs milled at the rotation speed of 48 $\mathrm{m} / \mathrm{s}$ using a inclined vibrating plate. Here, the maximum Newton's separation efficiency $\left(\eta_{\max }\right)$ are plotted against the vibration intensity $\left(K_{v}\right)$ of vibrating plate. Newton's separation efficiency, $\eta_{N}$ was calculated using the following relations.

$$
\begin{aligned}
& \eta_{N}=r_{m}-\left(1-r_{n}\right) \\
& r_{m}=\sum_{i=1}^{i} r_{m i} \\
& r_{n}=\sum_{i=j+1}^{11} r_{n i} \\
& r_{m i}=w_{i} \cdot x_{p i} / f \cdot x_{f} \\
& r_{n i}=w_{i} \cdot\left(1-x_{p i}\right) / f \cdot\left(1-x_{f}\right)
\end{aligned}
$$

where $f$ is the mass of feed particles, $x_{f}$ is the mass fraction of metal particles in the feed, $w_{i}$ is the mass of particles in vessel $i, x_{p i}$ is the mass fraction of metal particles in vessel $i$, and subscripts $m$ and $n$ denote metallic and nonmetallic components, respectively. $K_{v}$, the vertical component of vibration intensity, can be expressed by following equation.

$$
K_{v}=\mathrm{c} \omega^{2} \sin \alpha / g
$$

where $\omega$ is the angular frequency of vibration, $\alpha$ is the angle of throw of vibration, $c$ is the half-amplitude of vibration and $g$ is the acceleration of gravity. For particles larger than 297 $\mu \mathrm{m}, \eta_{\max }$ increases with $K_{v}$ showing a maximum at $K_{v}=$ 1.05 1.40. $\eta_{\max }$ decreases as $K_{v}$ exceeds 1.40. $\eta_{\max }$ for $297 \sim 149$ $\mu \mathrm{m}$ particles are lower than that of particles over $297 \mu \mathrm{m}$ showing a maximum at $K_{v}=1.40$.

Fig. 9 shows the maximum Newton's separation efficiency $\left(\eta_{\max }\right)$ of above particles which are shape sorted at various inclined angles using $K_{v}=1.40$. It can be seen that for both particle sizes $\eta_{\max }$ is obtained at inclined angle of $10^{\circ}$. From Figs. 8 and 9, it could be seen that the optimum conditions for shape sorting of metal particles using the inclined vibrating plate are obtained at $K_{v}=1.40$ and $\theta=10^{\circ}$. These values are in good agreement with the ones obtained by Koyanaka et al. (1995) for PWBs.

Fig. 10 shows the effect of rotation speed of hammer on the maximum Newton's separation efficiency $\left(\eta_{\max }\right)$ of these particles. The previously obtained optimum conditions of $K_{v}$ $=1.40$ and $\theta=10^{\circ}$ were used while rotation speeds were varied. For particles of over $297 \mu \mathrm{m}, \eta_{\max }$ increases with the hammer speed up to $48 \mathrm{~m} / \mathrm{s}$ over which it remained almost constant. However, it increases continuously in the case of $297 \sim 149 \mu$ m particles.

Fig. 11 shows the recovery of metals as a function of recovery location. Here, (a) is for particles larger than $297 \mu \mathrm{m}$ and $(\mathrm{b})$ is for $297 \sim 149 \mu \mathrm{m}$ particles. The other conditions $\left(K_{v}\right.$ $=1.40$ and $\theta=10^{\circ}$ ) were the same as before. By comparing (a) and (b) it is obvious that larger particles were recovered at locations nearer to the sample feeder. For particles over 297 $\mu \mathrm{m}$, the recovery maximum is located near $100 \mathrm{~mm}$ for most 


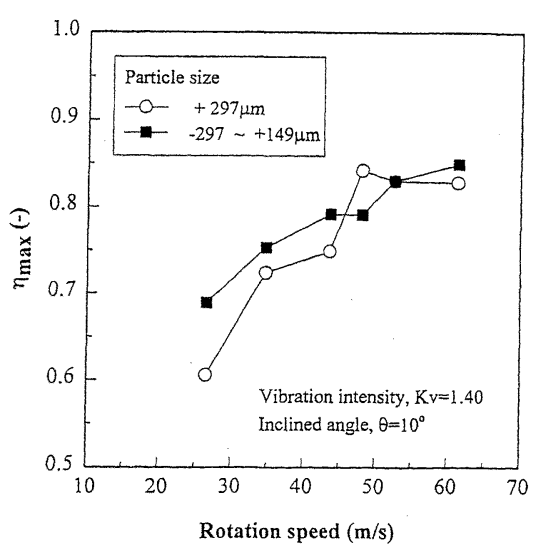

Fig. 10 The effect of rotation speed on the maximum Newtons' separation efficiency.
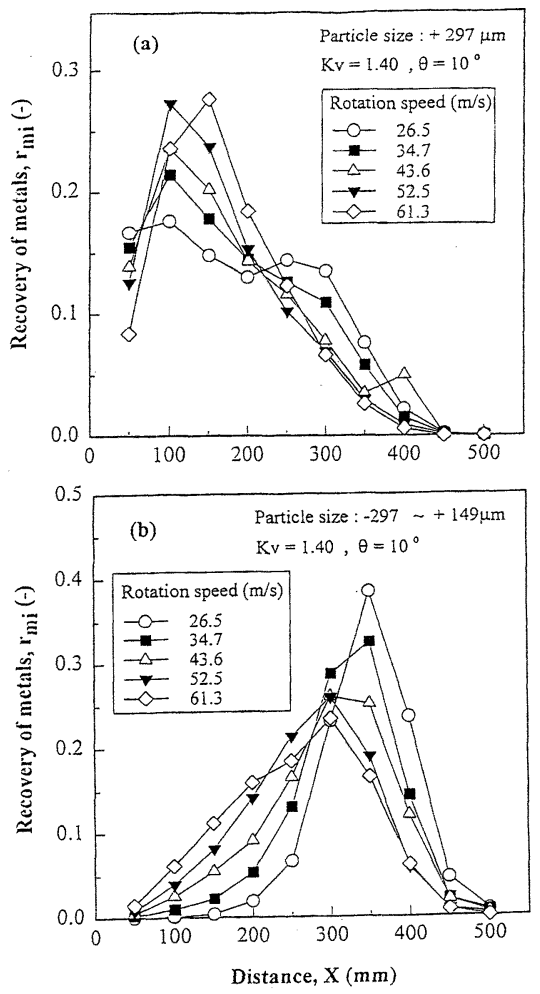

Fig. 11 Recovery of metal particles from PCBs. milled at various rotation speed.

(a) particles over $297 \mu \mathrm{m}$, (b) particles of $297 \sim 149$ $\mu \mathrm{m}$

of the rotation speed selected. For particles of $297 \sim 149 \mu \mathrm{m}$, the recovery maximum is located between $300 \sim 400 \mathrm{~mm}$ from the sample feeder. This suggests that larger particles are more spherical than smaller ones (Endoh, 1987).

Fig. 12 shows the average location and standard deviation calculated from data shown in Fig. 11 for the recovery of metal particles at various rotation speeds. For particles over $297 \mu \mathrm{m}$, the average location curve shows a minimum at 48 $\mathrm{m} / \mathrm{s}$. This behavior appears to be related to the observed maximum of $K I$ and the minimum of $\phi_{c}$ curves at the rotation speed as shown in Fig. 7. Both values represent the degree of roundness of particles. Therefore, it is obvious that shape of metal particles is the most spherical at this hammer speed of

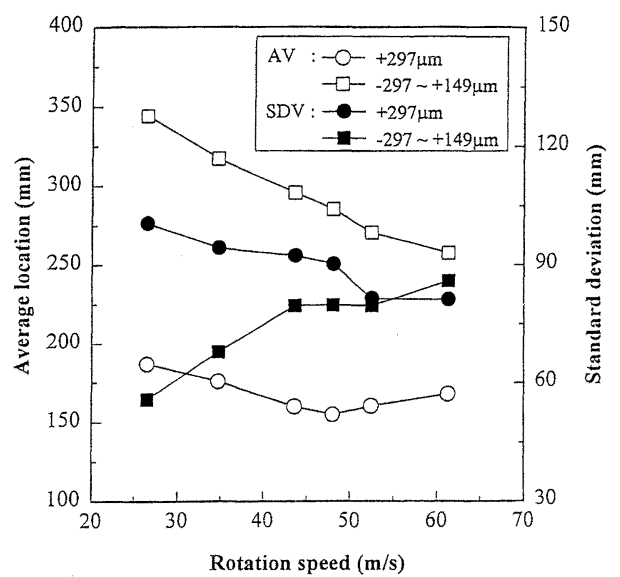

Fig. 12 The effect of rotation speed on the average location and standard deviation of recovery distribution.

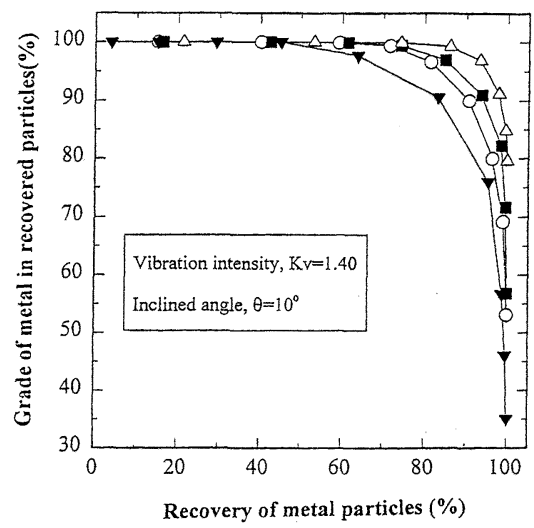

Fig. 13 Grade of metal particles recovered from milled PCBs. by the shape separation.

$48 \mathrm{~m} / \mathrm{s}$. In contrast, the average location of $297 \sim 149 \mu \mathrm{m}$ particles decreases continuously. This suggests that smaller particles become more spherical with increasing the rotation speed.

Standard deviation of recovery location for particles larger than $297 \mu \mathrm{m}$ decreases while that for $297 \sim 149 \mu \mathrm{m}$ particles increases suggesting that the shape homogeneity of larger particles improves as hammer speed increases. It is clear that particles of $297 \sim 149 \mu \mathrm{m}$ become more spherical but their shape homogeneity decreases. This explains the results of Fig. 11-b where the recovery location moves to the feeder with wider range of recovery location as the rotation speed of hammer increases.

Fig. 13 shows the recovery rate and grade of recovered metals at various recovery locations. They were milled at the speed of $48 \mathrm{~m} / \mathrm{s}$ and shape sorted at $K_{v}=1.40$ and $\theta=10^{\circ}$. To explore the effect of particle size on shape separation, the milled particles were divided into two ranges: one as $297 \sim 149$ $\mu \mathrm{m}$ and over $297 \mu \mathrm{m}$ the other as over $149 \mu \mathrm{m}$. For particles over $297 \mu \mathrm{m}$, it was possible to separate and recover metal particles maintaining high grades. The grade of metals was about $91 \%$ when the recovery rate was $97.9 \%$. For particles of $297 \sim 149 \mu \mathrm{m}$, the grade decreases abruptly as recovery rate increases. The recovery rate calculated for $297 \sim 149 \mu \mathrm{m}$ and 
over $297 \mu \mathrm{m}$ particles was $3 \sim 4 \%$ higher than that for over $149 \mu \mathrm{m}$ particles when compared at the same grade.

\section{Conclusions}

The recovery of metallic components from the spent printed circuit boards (PCBs) was conducted utilizing a swing hammer type impact mill and a shape separation technique. The results are summarized as follows.

(1) The apparent degree of liberation of metallic components increased with hammer speed reaching near $99 \%$ at the speed of $61.3 \mathrm{~m} / \mathrm{s}$.

(2) The $\mathrm{Sn} / \mathrm{Pb}$ ratio on $500 \mu \mathrm{m}$ copper particles decreased with hammer speed revealing a mechanochemical effect.

(3) The roundness over $500 \mu \mathrm{m}$ particles showed a maximum at $48 \mathrm{~m} / \mathrm{s}$. Meanwhile, particles of $297 \sim 149 \mu \mathrm{m}$ became more spherical with hammer speed though their shape homogeneity decreased.

(4) The optimum shape separation of metal particles by the inclined vibrating plate was obtained at $K_{v}=1.40$ and $\theta$ $=10^{\circ}$.

(5) For the particles over $297 \mu \mathrm{m}$, it was possible to recover metal with high recovery rate and grade. But the smaller the particles became, the more difficult to maintain metal grade was.
Acknowledgements One of the authors (J. Lee) would like to thank the Agency of Industrial Science and Technology (AIST) for the financial support provided through the ITIT program.

\section{References}

Day, J. G. (1984) : U. S. patent 4, 427, 442

Dunning, Jr., B. W. (1986) : Precious Metals Recovery Low Grade Resources, IC9059U. S. Bureau of Mines (Washington, DC. : ), p. 44-56

Edson, G. (1981) : Recovering and Refining of Precious Metals, IPMI (Skytop PA), Paper 10

Elaine, Y. L. Sun. (1991) : JOM, Vol. 43(4), p. 53-61

Endoh, S. (1987) : Powder Technol., Vol. 50, p. 103

Hedlund, L. and Johansson, L. (1985) : Recycle and Secondary Recovery of Metals (Taylor, P. R., Sohn, H. Y. and Jarrett, N., eds.), TMS, Warrecdale, PA), p. $787-796$

Hoffmann, J. E. (1992) : JOM, Vol. 44(7), p. 43-48

Kaltenboeck, J., Sauer, E., Woebking, H. and Woerz, H. (1985) : Metall. (Berlin), Vol. 39(11), p. 1047-1048

Koyanaka, S., Endoh, S. and Iwata, H. (1995) : J. Soc. Powder Technol., Japan, Vol. 32 , p. $385-391$

Krupka, D. and Chelminski, B. (1987) : Freiberger Forschungsh. B, B260, p. $88-91$

Masuda, Y., Miyabayashi, R. and Yamaguch, H. (1988) : Japan Kokai Tokkyo Koho, JP6311, 627 [8811, 627] (Cl. C22B11/02)

Setchfield, J. H. (1987) : Precious Metals (G. Vermeylen and R. Verbeeck eds.) IPMI (Allentowm, PA), p. 147-164

Rhee, K. I., Lee, J. C. and Lee, C. K. et al. (1995) : Third International Symposium on Recycling of Metals and Engineering Materials, (P. B. Queneau and R. D. Peterson eds. ), TMS, p. 469-478.

\section{形状分離法による廃 PCBs からの銅, 錫, 鉛などの有価金属の回収*}

\section{李 在 天 古屋 仲茂 樹 $^{2}$ 李敏 溶 $^{3}$ 大矢仁史 ${ }^{4}$ 遠藤茂 寿 $^{5}$}

廃 PCBs からの金属成分を分離・回収するために形状分離を行っ た。チップなどの電子部品を外した廃 PCBs をハンマミールで 1 $\mathrm{mm}$ 以下に粉砕し, 金属成分と非金属成分を単体分離した。単 体分離された金属成分と非金属成分を分離・回収するために，傾 斜振動板式形状分離機を用いて分離実験を行った。傾斜板の傾斜 角度および振動強度が分離効率に及ぼす影響などを検討した結果, 振動板の振動強度 $\left(K_{v}\right) 1.40$, 傾斜角度 $10^{\circ}$ で最適な分離効率を 得た。最適な分離条件で分離を行ったとき，金属成分を回収率お よび品位，ともに，90％以上で回収することができた。

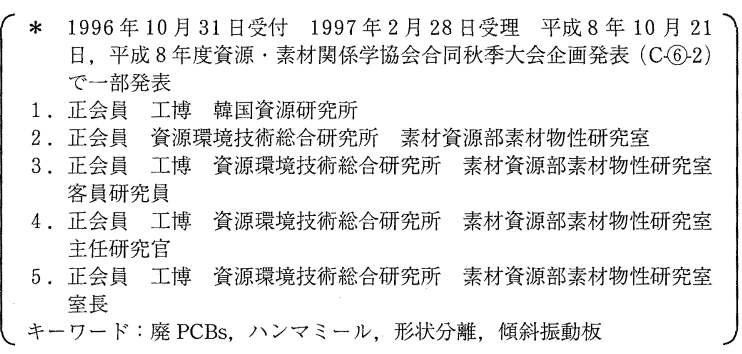

